\title{
Prevalence of Helicobacter pylori and the Interest of Its Eradication during the Functional Dyspepsia
}

\author{
S. Adadi', B. Bennani' ${ }^{2}$, M. Elabkari' ${ }^{1}$, A. Ibrahimi' ${ }^{1}$, S. Alaoui' ${ }^{2}$ M. El Khadir ${ }^{2}$, T. Harmouch ${ }^{3}$, \\ M. Mahmoud ${ }^{4}$, C. Nejjari5 ${ }^{5}$ D. Benajah' ${ }^{1}$
}

${ }^{1}$ Service of Hepatology and Gastroenterology, Hassan II University Hospital of Fez, University Sidi Mohamed Ben Abdellah, Fez, Morocco

${ }^{2}$ Microbiology and Molecular Biology Laboratory, Hassan II University Hospital of Fez, University Sidi Mohamed Ben Abdellah, Fez, Morocco

${ }^{3}$ Service Pathology, Hassan II University Hospital of Fez, University Sidi Mohamed Ben Abdellah, Fez, Morocco ${ }^{4}$ Service of Biology, Hassan II University Hospital of Fez, University Sidi Mohamed Ben Abdellah, Fez, Morocco ${ }^{5}$ Service of Épidémiology, Hassan II University Hospital of Fez, University Sidi Mohamed Ben Abdellah, Fez, Morocco

Email: safae.adadi@hotmail.fr

How to cite this paper: Adadi, S., Bennani, B., Elabkari, M., Ibrahimi, A., Alaoui, S., El Khadir, M., Harmouch, T., Mahmoud, M., Nejjari, C. and Benajah, D. (2018) Prevalence of Helicobacter pylori and the Interest of Its Eradication during the Functional Dyspepsia. Journal of Biosciences and Medicines, 6, 43-51.

https://doi.org/10.4236/jbm.2018.610006

Received: April 26, 2017

Accepted: October 13, 2018

Published: October 16, 2018

Copyright (C) 2018 by authors and Scientific Research Publishing Inc. This work is licensed under the Creative Commons Attribution International License (CC BY 4.0).

http://creativecommons.org/licenses/by/4.0/ (c) (i) Open Access

\begin{abstract}
Functional dyspepsia constitutes by its impact in quality of life and socio-economic impact areal public health problem (40\% of the adult population in the Western world). The prevalence of infection with Helicobacter pylori $(H P)$ in patients with functional dyspepsia is about $30 \%-70 \%$. The aim of our study is to observe the improvement of functional dyspepsia (FD) after Helicobacter pylori (HP) eradication. Methods: This is a prospective study over a period of 68 months (May 2009 - January 2015). We included all patients aged over 15 years, with functional dyspepsia defined by the Rome III criteria. The diagnosis of $H P$ was made by histology and/or PCR. Patients infected with $H P$ were treated in single-blind: standard triple therapy for 7 days or sequential treatment for 10 days. $H P$ eradication control was made after: 3 months, 6 months and one year of treatment. Results: During the study period, 1190 patients were included of which 250 patients (21\%) were in functional dyspepsia according to the Rome III criteria. The average age in patients with functional dyspepsia was 49 years [16 - 80], sex ratio M/F was 0.58 $(\mathrm{N}=92 / 158) .60 \%$ of patients were older than 45 years $(\mathrm{N}=150)$. Chronic smoking was found in $20 \%$ of patients $(\mathrm{N}=50)$. One hundred and seventy five patients $(70 \%)$ had $H P$ infection $(\mathrm{N}=175)$. One hundred and sixty five patients received the treatment of Helicobacter pylori (94.28\%), 10 patients were lost to follow (5.71\%). The eradication of $H P$ was obtained in $98.41 \%$ with sequential treatment versus $88.73 \%$ with standard triple therapy $(\mathrm{p}=$
\end{abstract}


0.026). All patients were reviewed at 3 months and 6 months after treatment, $86 \%$ were reviewed at 12 months $(\mathrm{N}=143)$. Dyspeptic symptoms was disappeared in $43 \%$ of our patients $(\mathrm{N}=71)$, partial disappearance of symptoms in $34.5 \%$ of cases $(\mathrm{N}=57)$, persistence of symptoms in $22.42 \%$ of cases $(\mathrm{N}=37)$. Conclusion: In our study the prevalence of Helicobacter pylori infection in patients with functional dyspepsia is high: $70 \%$. Sequential therapy is better than the standard triple therapy in the eradication of $H P$ in patients with non-ulcer dyspepsia, which improves their symptoms in more than $50 \%$ of cases.

\section{Keywords}

Functional Dyspepsia, Helicobacter pylori, Sequential Treatment, Triple Therapy

\section{Introduction}

Functional dyspepsia (FD) is defined, according to the Rome III criteria, such as abdominal discomfort or epigastric pain, no evidence of structural disease (including at upper endoscopy) that is likely to explain the symptoms. Criteria fulfilled for the last 3 months with symptom onset at least 6 months prior to diagnosis.

Functional dyspepsia constitutes by its impact in quality of life and socio-economic impact areal public health problem ( $40 \%$ of the adult population in the Western world). Functional dyspepsia has substantial financial implications for patients and negatively affects attendance and productivity in the workplace. Dyspepsia is usually a chronic condition in primary and secondary care. The costs in the United States remain poorly documented, but in Sweden a total societal cost of $\$ 63$ per adult was calculated for dyspepsia (including reflux disease) [1]. In another study, 288 adult primary care patients with dyspepsia were followed up for 1 year; dyspepsia patients ended to remain symptomatic with $61 \%$ using drugs and $43 \%$ having gastrointestinal procedures, indicating intensive use of medical resources [2].

The prevalence of infection with Helicobacter pylori $(H P)$ in patients with functional dyspepsia is about $30 \%-70 \%$. However, the role of $H P$ in the development of functional dyspepsia (FD) remains controversial.

The aim of our study is to determine the prevalence of $H P$ in patients with $\mathrm{FD}$ and to observe the improvement of FD after $H P$ eradication in a Moroccan population.

\section{Patients and Methods}

This is a prospective randomized study over a period of 4 years (May 2009 January 2015) in the service of Hepatology and Gastroenterology in hospital university Hassan II of Fez in collaboration with microbiology and molecular 
laboratory and epidemiology service of Faculty of Medicine and Pharmacy Fes. The study comparing the efficacy and safety of sequential treatment with standard triple therapy. We included all patients aged over 15 years, with digestive symptomatology. An upper endoscopy was performed in all patients, with five biopsies: two in the antrum, one at the angulus and two in the fundus. HP detection was done by histology and/or polymerase chain reaction (PCR).

From this study, we retrospectively studied a subgroup of patients with DF, defined according to the Rome III criteria.

During the study period, 1190 patients were included, 250 patients (21\%) were in functional dyspepsia according to the Rome III criteria.

\section{1) Inclusion Criteria}

Adult patients, presenting DF defined according to the Rome III criteria, with $H P$ infection determined by pathological examination and/or PCR, naïve to treatment. Patient's consent was obtained.

\section{2) Randomization}

The patients included in study are randomized in single-blind into three treatment groups:

- Group AM (N = 40): (IPP 20 mg + Amoxicillin 1 g + métronidazol 500 mg) taken twice a day for 7 days.

- Group AC (N = 50): (IPP $20 \mathrm{mg}+$ Amoxicillin $1 \mathrm{~g}+$ clarithromycin 500 $\mathrm{mg})$ taken twice a day for 7 days.

- Group SQ (N = 75): (IPP $20 \mathrm{mg}+$ Amoxicillin $1 \mathrm{~g}$ ) taken twice a day for 5 days and then (IPP $20 \mathrm{mg}+$ Metronidazol $500 \mathrm{mg}+$ Clarithromycin $500 \mathrm{mg}$ ) taken twice a day for 5 days.

\section{3) Study Process}

The aim of our study is to observe the improvement of functional dyspepsia (FD) after Helicobacter pylori (HP) eradication "the variable that needed to test is the improvement of symptoms of FD" * oo the study was conducted over five visits:

- Inclusion visit: inclusion of the patients.

- End of treatment visit: evaluation of adherence of treatment and drug tolerance.

- HP eradication control (at 3 months): The eradication of $H$. pylori control was based on the breath test with marked urea' this visit also constitutes a first evaluation of the symptoms of functional dyspepsia.

- The visits at 6 months and 12 months of treatment: evaluation of symptoms, control of maintains of the eradication of $H p$ and diagnosis of possible reinfestation, by a breath test.

\section{4) Symptom Evaluation}

- The persistence of symptoms defined by the non-improvement of symptoms of functional dyspepsia at 3 months, 6 months and 12 months of therapy of $H P$.

- The partial improvement of symptoms: improvement of more than 50\% of 
the symptoms of functional dyspepsia at 12 months of the eradication of $H P$.

- Total improvement: disappearance of the totality of symptoms of functional dyspepsia at 12 months of the eradication of $H P$.

\section{Results}

During the study period, 1190 patients were included, 250 patients (21\%) were in functional dyspepsia according to the Rome III criteria.

One hundred and seventy five patients $(70 \%)$ had $H P$ infection $(\mathrm{N}=175)$. The diagnosis of $H P$ was made by histology and/or PCR. One hundred sixty five patients were randomized and treated into three treatment groups AC, AM and SQ, 10 patients were lost to follow.

The results were processed by the SPSS version 20 software.

\section{Epidemiological characteristics of patients}

As presented in Table 1, the average age in patients with functional dyspepsia was 49 years [16 - 80], sex ratio M/F was $0.58(\mathrm{~N}=92 / 158)$. Sixty percent of patients were older than 45 years $(\mathrm{N}=150)$. Chronic smoking was found in $20 \%$ of patients $(\mathrm{N}=50)$, alcoholism was found in $8 \%$ of our patients $(\mathrm{N}=20)$.

In univariate analysis comparing the two groups of dyspeptic patients: $H P$ positive and $H P$ negative, only the taking of non steroidal anti inflammatory was significantly higher in the $H P$ negative group $(\mathrm{p}=0.021)$.

An upper endoscopy was done in all our patients, it was normal in $6 \%$ of cases $(\mathrm{N}=15)$, gastritis was found in $94 \%$ of cases $(\mathrm{N}=235)$.

$H P$ eradication and its impact in the evolution of the symptoms of dyspepsia

As mentioned in Table 2, forty six percent of patients was treated by the sequential treatment (it's mean group $\mathrm{SQ})(\mathrm{N}=75)$ eradication rate in this group was $98.4 \%$ versus $88.7 \%$ in the group treated by standard triple therapy (it's mean AM and AC group) ( $\mathrm{p}=0.026)$.

The eradication rate with the sequential treatment was statistically superior to the standard triple therapy $(p=0.026)$, but there was no difference between the two treatments (sequential therapy versus standard triple therapy) in terms of impact in the symptoms of functional dyspepsia $(\mathrm{p}=0.59)$.

\section{Symptoms evaluation}

All patients were reviewed at 3 months and 6 months, 86\% were reviewed at 12 months $(\mathrm{N}=142)$. Dyspeptic symptoms have been disappeared in $43 \%$ of cases $(\mathrm{N}=71)$. Partial disappearance of symptoms in $34.5 \%$ of cases $(\mathrm{N}=57)$, persistence of symptoms in $22.42 \%$ of cases $(\mathrm{N}=37)$. The results are presented in Table 3.

\section{Predictors factors of persistent symptoms of functional dyspepsia}

In univariate analysis nor age $(\mathrm{p}=0.24)$ nor gender $(\mathrm{p}=0.21)$ nor smoking $(\mathrm{p}$ $=0.22)$ nor alcoholism $(\mathrm{p}=0.48)$ nor weight $(\mathrm{p}=0.97)$ and neither the cure of Helicobacter pylori $(\mathrm{p}=0.28)$ were associated with persistent symptoms of functional dyspepsia. 
Table 1. Epidemiological characteristics of patients.

\begin{tabular}{ccc}
\hline & Number of patients & Percentage \\
\hline Total number of patients with FD & 250 & \\
$H P$ infection rate & 175 & $70 \%$ \\
average age & 49 years $[16-80]$ & \\
Sex-ratio M/F & 0.58 & \\
Tobacco & 50 & $20 \%$ \\
Alcoholism & 20 & $8 \%$ \\
Endoscopy: & & $6 \%$ \\
Normal & 15 & $94 \%$ \\
Gastritis & 235 & \\
\hline
\end{tabular}

Table 2. Eradication of $H$. pylori.

\begin{tabular}{cccc}
\hline $\begin{array}{c}\text { Eradication } \\
\mathbf{N}=165\end{array}$ & $\begin{array}{c}\text { Triple therapy } \\
\mathbf{N}=90 / 165\end{array}$ & $\begin{array}{c}\text { Sequential treatment } \\
\mathbf{N}=75 / 165\end{array}$ & $\mathrm{p}$ \\
\hline $93.28 \%$ & $88.7 \%$ & $98.4 \%$ & 0.026 \\
\hline
\end{tabular}

Table 3. Relationship between $H$. pylori cure and the improvement of symptoms of FD.

\begin{tabular}{cccccc}
\hline H. pylori cure & $\begin{array}{c}\text { Persistence of } \\
\text { symptoms }\end{array}$ & $\begin{array}{c}\text { Partial } \\
\text { disappearance of } \\
\text { symptoms }\end{array}$ & $\begin{array}{c}\text { Disappearance of } \\
\text { symptoms }\end{array}$ & Total & $\mathrm{p}$ \\
\hline $\begin{array}{c}\text { Triple therapy } \\
\begin{array}{c}\text { Sequential } \\
\text { treatment }\end{array}\end{array}$ & $\mathrm{N}=19$ & $\mathrm{~N}=32$ & $\mathrm{~N}=39$ & $90 / 165$ & \\
\hline
\end{tabular}

\section{Discussion}

Functional dyspepsia constitutes a real clinical problem because of its complex physiopathology, the heterogeneity of the clinical presentation and difficult of its management [3].

Given the high prevalence of Helicobacter pylori (HP) in our country (around $69 \%$ ), and the relationship between this bacterium and FD [4], it's important to study the benefit of eradicating $H P$ in dyspeptic patients in order to avoid costly prescription.

$H P$ is currently considered to be the major etiological factor in the development of gastritis, peptic ulcer disease (PUD), gastric cancer and lymphoma of mucosa-associated lymphoid tissue (MALT) [5]. However, the role of $H P$ in the development of functional dyspepsia (FD) remains controversial [6]. One of the main arguments behind the possible role of this bacterium (HP) in the development of non-ulcer dyspepsia is derived from clinical experience, through a systematic evaluation showing the positive impact of $H P$ eradication in the symptoms of DF [7].

The prevalence of $H P$ is about $30 \%$ in developed countries [8] and $80 \%-90 \%$ in developing countries [9]. However the prevalence of $H P$ in FD, varies between 
$30 \%$ to $70 \%[6][10]$.

In our study, the prevalence of HP in patients with DF was $70 \%$, it's a high prevalence but concordant with data of other studies, so in a series of $664 \mathrm{Chi}-$ nese patients with DF, helicobacter pylori was found in $67.7 \%$ of patients [6].

By comparing the epidemiological characteristics of our patients with FD with $H P$ positive and those who are not infected with $H P$, we find that only the nonsteroidal anti-inflammatory drugs (NSAID) is significantly higher in the negative $H P$ group $(\mathrm{p}=0.021)$ Which could explain dyspeptic symptoms in this group of patients, the causal link between the use of certain drugs, in particular NSAID and the appearance of dyspeptic symptoms, is clearly established [3].

Concerning smoking and alcohol, the results of scientific studies are controversial, their link with the onset of dyspeptic symptoms is poorly understood, thus, in a large Chinese serie, including 1049 patients with FD according to the Rome III criteria, in univariate analysis, alcohol is a factor related to FD ( $\mathrm{p}=$ $0.024)$ [11]. In our study, neither chronic smoking nor alcohol consumption was significantly related to dyspeptic symptoms.

Among other factors related to DF, psychological disorders have been the subject of many studies [3] [12], particularly anxiety, which is a well-documented [13], the association of anxiolytic treatment and antidepressant therapy may improve the symptoms of some patients [14]. Unfortunately we cannot through our study, prove this relationship because the psychological factor was not taken into account in the collection of our data.

All of our dyspeptic patients infected with $H P$ were treated either by sequential treatment or by triple therapy, and we have demonstrated superiority of sequential treatment in eradication of $H P$ [98.41\% versus $88.73 \%](\mathrm{p}=0.026)$, unlike In a randomized prospective multicenter cohort study in China, which did not find any significant difference in the rate of $H P$ eradication between the two groups (triple therapy versus sequential therapy) [6].

Many studies were focused on the interest of $H P$ eradication in dyspeptic patients, some of them have reported a beneficial effect [15] [16] [17]. Some study observed no differences in symptoms in the successful and non-successful $H P$ eradication groups [18] [19] [20]. The number needed to treat for one patient to have relief of symptoms is 15 [21]. However, after $H P$ eradication, the profit persists in the long term [22].

In our study, $H P$ eradication in dyspeptic patients has improved the symptoms in over $50 \%$ of cases, justifying the attitude: test and treat $H P$ in patients with non-ulcer dyspepsia [23].

The eradication of $H P$ in dyspeptic patients, According to our study, improved symptoms in more than $50 \%$ of cases, but we do not have a control group of dyspeptic patients infected with $H P$ and not eradicated, which would to obtain a statistically significant comparison, And to recommend, to eradicate systematically this bacterium in dyspeptic patients.

In our study the statistical analysis showed that neither age $(\mathrm{p}=0.24)$ nor sex $(\mathrm{p}=0.21)$ nor smoking $(\mathrm{p}=0.22)(\mathrm{p}=0.48)$, weight $(\mathrm{p}=0.97)$, and neither He- 
licobacter pylori eradication $(\mathrm{p}=0.28)$ were not related to the persistence of symptoms of non-ulcer dyspepsia, however, a Japanese study published in 2013, Found, in univariate analysis, that $H P$ eradication, male sex, higher than normal BMI, and an antecedent of psychotherapy or anxiolytic treatment were significantly related to the improvement of symptoms of FD at 3 months and 12 months [24].

\section{Conclusion}

Non-ulcer dyspepsia is a pathology whose pathophysiology is complex and probably multifactorial. Many pathogenic factors have been incriminated: genetic, environmental, pathological and psychological factors [25]. Psychosocial factors such as depression, anxiety and stressful life events are important factors in the development of a DF [26]. The relationship between Helicobacter pylori and DF has also been reported [27]. However, it still seems difficult to establish a direct link between $H P$ and the symptoms of non-ulcer dyspepsia, the interest of systematic eradication is still the object of controversy. Nevertheless, given the high prevalence of this bacterium in our country, and its incrimination in several digestive pathologies, it seems logical to eradicate it when the diagnosis is made.

\section{Conflicts of Interest}

The authors declare no conflicts of interest regarding the publication of this paper.

\section{References}

[1] Agreus, L., Borgquist, L. (2002) The Cost of Gastro-Oesophageal Reflux Disease, Dyspepsia and Peptic Ulcer Disease in Sweden. PharmacoEconomics, 20, 347-355. https://doi.org/10.2165/00019053-200220050-00006

[2] Quartero, A.O., Numans, M.E., Post, M.W.M., et al. (2002) One-Year Prognosis of Primary Care Dyspepsia: Predictive Value of Symptom Pattern, Helicobacter pylori and GP Management. European Journal of Gastroenterology \& Hepatology, 14, 55-60. https://doi.org/10.1097/00042737-200201000-00010

[3] Voiosu, T.A., et al. (2013) Functional Dyspepsia Today. Maedica, 8, 68-74.

[4] Talley, N.J. and Choung, R.S. (2009) Whither Dyspepsia? A Historical Perspective of Functional Dyspepsia, and Concepts of Pathogenesis and Therapy in 2009. Journal of Gastroenterology and Hepatology, 24, S20-S28.

https://doi.org/10.1111/j.1440-1746.2009.06067.x

[5] Sanders, M.K. and Peura, D.A. (2002) Helicobacter pylori-Associated Diseases. Current Gastroenterology Reports, 4, 448-454. https://doi.org/10.1007/s11894-002-0019-x

[6] Xu, S., et al. (2013) Symptom Improvement after Helicobacter pylori Eradication in Patients with Functional Dyspepsia-A Multicenter, Randomized, Prospective Cohort Study. International Journal of Clinical and Experimental Medicine, 6, 747-756.

[7] Moayyedi, P., Soo, S., Deeks, J., et al. (2006) Eradication of Helicobacter pylori for Non-Ulcer Dyspepsia. Cochrane Database of Systematic Reviews, No. 2, Article ID: CD002096. 
[8] Everhart, J.E. (2000) Recent Developments in the Epidemiology of Helicobacter pylori. Gastroenterology Clinics of North America, 29, 559-578. https://doi.org/10.1016/S0889-8553(05)70130-8

[9] Lacy, B.E. and Rosemore, J. (2001) Helicobacter pylori: Ulcers and More: The Beginning of an Era. Journal of Nutrition, 131, 2789S-2793S. https://doi.org/10.1093/jn/131.10.2789S

[10] Armstrong, D. (1996) Helicobacter pylori Infection and Dyspepsia. Scandinavian Journal of Gastroenterology, 215, 38-47. https://doi.org/10.3109/00365529609094532

[11] Jiao, Y., et al. (2013) Gastrointestinal Symptoms and Associated Factors in Chinese Patients with Functional Dyspepsia. World Journal of Gastroenterology, 19, 5357-5364. https://doi.org/10.3748/wjg.v19.i32.5357

[12] Budavari, A.I. and Olden, K.W. (2003) Psychosocial Aspects of Functional Gastrointestinal Disorders. Gastroenterology Clinics of North America, 32, 477-506. https://doi.org/10.1016/S0889-8553(03)00030-X

[13] Aro, P., Talley, N.J., Ronkainen, J., et al. (2009) Anxiety Is Associated with Uninvestigated and Functional Dyspepsia (Rome III Criteria) in a Swedish Population Based Study. Gastroenterology, 137, 94-100. https://doi.org/10.1053/j.gastro.2009.03.039

[14] Hashash, J.G., Abdul-Baki, H., Azar, C., et al. (2008) Clinical Trial: A Randomized Controlled Cross over Study of Flupenthixol + Melitracen Infunctional Dyspepsia. Alimentary Pharmacology \& Therapeutics, 27, 1148-1155. https://doi.org/10.1111/j.1365-2036.2008.03677.x

[15] Loyd, R.A. and McClellan, D.A. (2011) Update on the Evaluation and Management of Functional Dyspepsia. American Family Physician, 83, 547-552.

[16] Danesh, J., Lawrence, M., Murphy, M., et al. (2000) Systematic Review of the Epidemiological Evidence on Helicobacter Pylori Infection and Nonulcer or Uninvestigated Dyspepsia. Archives of Internal Medicine, 160, 167-180. https://doi.org/10.1001/archinte.160.8.1192

[17] McColl, K., et al. (1998) Symptomatic Benefit from Eradicating Helicobacter pylori Infection in Patients with Nonulcerdyspepsia. The New England Journal of Medicine, 339, 1869-1874. https://doi.org/10.1056/NEJM199812243392601

[18] Blum, A., Talley, N., O’Morain, C., van Zanten, S.V., Labenz, J., Stolte, M., et al. (1998) Lack of Effect of Treating Helicobacter pylori Infection in Patients with Nonulcer Dyspepsia. The New England Journal of Medicine, 339, 1875-1881. https://doi.org/10.1056/NEJM199812243392602

[19] Talley, N.J., Vakil, N., Ballard, E.D. and Fennerty, M.B. (1999) Absence of Benefit of Eradicating Helicobacter pylori in Patients with Nonulcer Dyspepsia. The New England Journal of Medicine, 341, 1106-1111.

https://doi.org/10.1056/NEJM199910073411502

[20] Ladrón de Guevara, L., Peña-Alfaro, N.G., Padilla, L., Lichtinger, A., Figueroa, S., Shapiro, I., et al. (2004) Evaluation of Symptomatology and Quality of Life in Functional Dyspepsia before and after Helicobacter pylori Eradication Treatment. Revista de Gastroenterología de México, 69, 203-208.

[21] Longstreth, G.F. (2006) Functional Dyspepsia-Managing the Conundrum. The New England Journal of Medicine, 354, 791-793. https://doi.org/10.1056/NEJMp058326

[22] Harvey, R.F., et al. (2010) Clinical Trial: Prolonged Beneficial Effect of Helicobacter pylori Eradication on Dyspepsia Consultations. The Bristol Helicobacter Project. Alimentary Pharmacology \& Therapeutics, 32, 394-400. https://doi.org/10.1111/j.1365-2036.2010.04363.x 
[23] Talley, N.J. and Vakil, N. (2005) Practice Parameters Committee of the American College of Gastroenterology. Guidelines for the Management of Dyspepsia. The American Journal of Gastroenterology, 100, 2324-233. https://doi.org/10.1111/j.1572-0241.2005.00225.x

[24] Kim, S.E., et al. (2013) Effect of Helicobacter pylori Eradication on Functional Dyspepsia. Journal of Neurogastroenterology and Motility, 19, 233-243. https://doi.org/10.5056/jnm.2013.19.2.233

[25] Miwa, H., et al. (2011) Current Understanding of Pathogenesis of Functional Dyspepsia. Journal of Gastroenterology and Hepatology, 26, 53-60. https://doi.org/10.1111/j.1440-1746.2011.06633.x

[26] Van Oudenhove, L., et al. (2008) Determinants of Symptoms in Functional Dyspepsia: Gastric Sensorimotor Function, Psychosocial Factors or Somatisation? Gut, 57, 1666-1673. https://doi.org/10.1136/gut.2008.158162

[27] Ford, A.C., et al. (2005) Helicobacter pylori “Test and Treat" or Endoscopy for Managing Dyspepsia: An Individual Patient Data Meta-Analysis. Gastroenterology, 128, 1838-1844. https://doi.org/10.1053/j.gastro.2005.03.004 